\title{
A EDUCAÇÃO DE JOVENS E ADULTOS NO PLANO NACIONAL DE EDUCAÇÃO: AVALIAÇÃO, DESAFIOS E PERSPECTIVAS
}

\author{
Maria Clara Di Pierro*
}

\begin{abstract}
RESUMO: O artigo contextualiza e avalia os resultados do Plano Nacional de Educação (PNE) 2001-2010, evidenciando que as metas para a educação de jovens e adultos (EJA) não serão alcançadas. Analisa a abordagem conferida à EJA nos documentos preparatório e final da Conferência Nacional de Educação (CONAE) e indica desafios prioritários desse campo educativo a serem enfrentados pelo novo PNE 2011-2020 nos âmbitos das concepções político-pedagógicas, do financiamento, da formação e profissionalização dos educadores e do regime de colaboração entre as esferas de governo.
\end{abstract}

Palavras-chave: Educação de jovens e adultos. Planejamento educacional. Políticas educacionais.

\section{YOUTH AND ADULT EDUCATION IN THE NATIONAL PLAN FOR EDUCATION: ASSESSMENT, CHALLENGES AND PERSPECTIVES}

ABSTRACT: This paper contextualizes and assesses the results of the 2001-2010 National Plan for Education. It clearly demonstrates that the goals for youth and adult education (YAE), established by Law 10.172, will not be reached. It analyzes the approach given to YAE in the preparatory and final documents of the Brazilian Conference on Education. The main challenges that the new National Plan for Education 2011-2020 will have to face in this field of education concern political-pedagogical concepts,

Doutora em Educação e professora da Faculdade de Educação da Universidade de São Paulo (UsP).E-mail:mcpierro@usp.br 
funding, educator formation and professionalization, as well as collaboration among the different spheres of government.

Key words: Youth and adult education. Educational planning. Education policies.

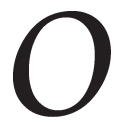

caminho que leva à construção do novo plano plurianual de educação passa pelo diagnóstico da situação atual e por uma visão dos desafios futuros, mas exige também um olhar retrospectivo sobre o percurso de formulação e implementação do plano anterior, para avaliar o alcance das metas então fixadas e compreender os fatores que incidiram sobre os resultados alcançados. Essa revisão é especialmente necessária quando está em tela a EJA, âmbito em que é flagrante o insucesso das políticas públicas frente à meta de superação do analfabetismo, mencionada na Constituição Federal e nos compromissos assumidos pelo país em fóruns internacionais.

\section{Um olhar retrospectivo para o PNE 2001-2010}

O período de 1996 a 2001, em que se desenrolou o processo de construção do PNE que resultou na Lei n. 10.172, foi marcado por controvérsias sobre a importância relativa da EJA na agenda de políticas educacionais. Quando dirigimos a atenção para as retóricas educativas, os acordos internacionais e a legislação nacional do período, somos levados a crer na existência de um amplo consenso em torno do direito humano à educação, em qualquer idade, e à necessidade da formação continuada ao longo da vida. Entretanto, quando analisamos as políticas educacionais levadas à prática, constatamos a secundarização da EJA frente a outras modalidades de ensino e grupos de idade.

Iniciada em 1990 com a Conferência Mundial de Jontiem, a Década da Educação para Todos se propunha não só a assegurar que todas as crianças e adolescentes tivessem acesso de ensino de qualidade, com equidade de gênero, mas também a reduzir pela metade os índices de analfabetismo e proporcionar aos jovens e adultos as oportunidades para satisfação de suas múltiplas necessidades de aprendizagem. ${ }^{1}$ Em meados da década de 1990 , a Comissão Internacional sobre a Educação para o século XXI difundiu o Relatório Jacques Delors, 
que reiterou ser a educação um bem coletivo, ao qual todas as pessoas deveriam ter acesso; e, em 1997, a v Conferência Internacional de Educação de Adultos comprometeu os países signatários da Declaração de Hamburgo com a promoção da aprendizagem ao longo da vida. Também no âmbito nacional, a Lei n. 9.394 de Diretrizes e Bases da Educação Nacional (LDBEN), de 1996, reiterou os direitos educativos dos jovens e adultos ao ensino adequado às suas necessidades e condições de aprendizagem e estabeleceu as responsabilidades dos poderes públicos na identificação e mobilização da demanda, e na provisão de ensino fundamental gratuito e apropriado.

No decorrer da segunda metade da década de 1990, entretanto, o território concreto da formulação e implementação das políticas governamentais no Brasil mostrou-se bastante problemático para a EJA, especialmente quando considerada a atuação do governo federal que, historicamente, cumpre importante papel de indução de iniciativas dos estados e municípios nesse campo educativo (Beisiegel, 2003). Num contexto de redefinição dos papéis do Estado e de contenção do gasto federal, a política educacional do governo do Presidente Fernando Henrique Cardoso (1995-2002) induziu à municipalização e focalizou o investimento público no ensino fundamental de crianças e adolescentes, mediante a criação, em 1996, de fundos de financiamento em cada uma das unidades da Federação. Por força de veto presidencial à lei que regulamentou o Fundo de Manutenção e Desenvolvimento do Ensino Fundamental e de Valorização do Magistério (FUNDEF), as matrículas na EJA não puderam ser consideradas, o que restringiu as fontes de financiamento e desestimulou os gestores a ampliarem as matrículas na modalidade.

Nesse período, a relação da União com os governos subnacionais foi marcada pela centralização dos instrumentos de regulação da política de EJA, mediante a prescrição de referenciais curriculares nacionais, a uniformização de materiais didáticos e das ações de formação docente em serviço e a criação de um exame nacional de certificação de competências. De outro lado, teve continuidade o processo de desconcentração das responsabilidades pelo financiamento e provisão dos serviços educativos, observando-se nítida tendência à municipalização das matrículas na etapa do ensino fundamental. A colaboração do governo federal para a manutenção e o desenvolvimento da EJA - consubstanciada nos programas Alfabetização Solidária $(\mathrm{PAS})^{2}$ e Recomeço ${ }^{3}$ - obedeceu 
A educação de jovens e adultos no Plano Nacional de Educação...

à diretriz da focalização, restringindo-se aos estados e municípios com maiores taxas de analfabetismo e menores índices de desenvolvimento humano, localizados no Nordeste e Norte do país.

Persistiu a histórica escassez de oportunidades de formação para os educadores da EJA e nenhuma medida de política educacional foi tomada para reverter essa situação, de modo que, no início do terceiro milênio, pouco mais de $1 \%$ dos cursos de formação docente no país ofereciam habilitação específica para atuar com essa modalidade da educação básica (Di Pierro, Abbonizio \& Graciano, 2004; Soares, 2010).

O discurso técnico-político que justificou a secundarização da formação dos adultos na agenda da política educacional apoiava-se no suposto caráter profilático das medidas que priorizavam a formação das novas gerações, com base no argumento propalado por organismos multilaterais de crédito e assessoramento de que os investimentos na EJA mostravam-se pouco efetivos (Torres, 2002).

O governo procurou silenciar a resistência a esse tipo de perspectiva, suspendendo em 1996 as atividades da Comissão Nacional de Educação de Jovens e Adultos criada no governo anterior, mas as vozes dissonantes encontraram outros canais de expressão nos fóruns de EJA que proliferaram nos estados a partir daquele ano (Di Pierro, 2008; Soares, 2003).

Esse foi, no campo da EJA, o contexto em que se originaram as propostas da administração federal e da sociedade civil para o PNE apresentadas ao Congresso em 1998.

\section{As propostas para a EJA nos anteprojetos do governo e da sociedade}

As duas propostas de PNE que chegaram ao Congresso não diferiam quanto às concepções de formação de pessoas jovens e adultas, não aderiam a perspectivas inovadoras, nem se alinhavam aos paradigmas da educação popular ou da educação continuada ao longo da vida. Ambos os documentos limitavam-se a desenhar estratégias de elevação das taxas de alfabetização e níveis de escolaridade da população, ocupando-se da reposição de estudos não realizados na infância ou adolescência, o que os situa nos marcos da concepção compensatória da EJA.

Atendendo à Constituição e à LDBEN, que determinam que os planos plurianuais conduzam à universalização da alfabetização e do 
atendimento escolar, os dois documentos ofereciam metas ousadas de superação do analfabetismo absoluto e funcional. ${ }^{4}$ A proposta governamental visava assegurar acesso universal ao primeiro segmento do ensino fundamental a toda a população jovem e adulta, conferindo prioridade de atendimento aos grupos de idade mais jovens; o plano da II CONED ampliava essa meta para o ensino fundamental completo, também focalizando a população de 14 a 35 anos. A proposta do Executivo projetava quadruplicar a capacidade de atendimento em cursos para jovens e adultos de nível médio, enquanto a meta indicada pela II CONED era, no prazo de cinco anos, estender a todas as escolas públicas a oferta de EJA em ambas as etapas dos ensinos fundamental e médio. O governo planejava implantar cursos de ensino básico e formação profissional em todo o sistema prisional e nos estabelecimentos onde adolescentes em conflito com a lei cumprem medida socioeducativa em regime fechado, aspecto este não mencionado no documento elaborado pelas organizações da sociedade civil. O inverso ocorria quando o assunto era a educação de pessoas com deficiência, lembrado pela proposta da CONED e esquecido no documento do governo. Os dois projetos indicavam estratégias complementares como a elaboração de materiais didáticos, formação de educadores e parcerias entre o setor público e as organizações comunitárias no desenvolvimento dos programas de EJA.

A distinção mais evidente entre os dois projetos residia nos critérios e mecanismos de financiamento da EJA. O documento governamental não propunha novas fontes ou mecanismos de financiamento, recomendando que os estados e municípios financiassem a modalidade com os recursos vinculados não capturados pelo FUNDEF. Já o plano proposto pela CONED projetava um investimento crescente em EJA de $0,4 \%$ a $1 \%$ do Produto Interno Bruto (PIB), para cobrir um custo aluno-ano estimado em $\mathrm{R} \$ 1$ mil; tais recursos seriam obtidos mediante a inserção da EJA no sistema de financiamento da educação básica, da qual foi excluída em virtude do veto presidencial à Lei n. 9.424/1996 que regulamentou o FUNDEF.

Ao longo dos dois anos em que os projetos de PNE tramitaram nas duas casas do Congresso, a EJA foi abordada em apenas uma audiência pública convocada pela Comissão de Educação da Câmara dos Deputados, em junho de 1999, que também tratou da educação indígena e do ensino a distância, o que restringiu o aprofundamento de cada 
A educação de jovens e adultos no Plano Nacional de Educação...

um dos temas. Os especialistas convidados criticaram a estratégia de campanha de alfabetização e a inclinação dos governos delegarem às organizações sociais encargos por sua manutenção e desenvolvimento, sublinhando a responsabilidade do setor público pela ampliação das oportunidades educativas com qualidade e pela inserção orgânica da modalidade ao sistema de ensino, o que exigia ampliação do financiamento. Mencionou-se que a alfabetização e o analfabetismo articulamse às condições socioeconômicas e a outros mecanismos de inclusão e exclusão sociocultural, cuja transformação requer processos continuados de formação integrados a políticas de acesso ao trabalho e à renda. Ponderou-se que o desempenho escolar das novas gerações depende de seu ambiente de socialização primária, nas famílias e comunidades, motivo pelo qual o investimento realizado em EJA é fator de melhoria do sistema educacional em seu conjunto.

\section{A EJA na lei que instituiu o PNE}

O capítulo dedicado à EJA no PNE aprovado pelo Congresso na forma da Lei n. 10.172/2001 teceu um diagnóstico que reconheceu a extensão do analfabetismo absoluto e funcional e sua desigual distribuição entre as zonas rural e urbana, as regiōes brasileiras, os grupos de idade, sexo e etnia. O Plano admitia ser insuficiente apostar na dinâmica demográfica e atuar apenas junto às novas geraçóes, propondo que as ações de escolarização atingissem também os adultos e idosos.

Nas diretrizes, o PNE aderiu à concepção de educação continuada ao longo da vida, mas priorizou a atenção ao direito público subjetivo dos jovens e adultos ao ensino fundamental público e gratuito. O capítulo sobre EJA enunciou 26 metas, dentre as quais se destacavam cinco objetivos: 1) alfabetizar, em cinco anos, dez milhões de pessoas, de modo a erradicar o analfabetismo em uma década; 2) assegurar, em cinco anos, a oferta do primeiro ciclo do ensino fundamental a metade da população jovem e adulta que não tenha atingido esse nível de escolaridade; 3) oferecer, até o final da década, cursos do segundo ciclo do ensino fundamental para toda a população de 15 anos ou mais que concluiu as séries iniciais; 4) dobrar, em cinco anos, e quadruplicar, em dez anos, a capacidade de atendimento nos cursos de EJA de nível médio; 5) implantar ensino básico e profissionalizante em todas as unidades prisionais e estabelecimentos que atendem a adolescentes infratores. 
Para cumprir essas metas, previa-se cooperação entre as três esferas de governo e a sociedade civil organizada, e o incremento de recursos financeiros, mas, no capítulo sobre financiamento, prevaleceu a proposta do executivo federal de emprego prioritário na EJA dos recursos destinados ao ensino fundamental que não integravam o FUNDEF.

Embora mencionasse a necessidade de especialização do corpo docente, o Plano previu apenas que os estados mantivessem programas de formação de educadores para atuar na alfabetização e séries iniciais da EJA. Perdeu-se, assim, a oportunidade de convocar as instituiçôes de ensino superior a considerar esse aspecto na formação inicial de professores e também a se engajar na formação continuada de docentes que atuam em projetos comunitários e nas redes públicas de ensino.

Ainda que o diagnóstico tenha reconhecido a necessidade de políticas focalizadas para reverter as desigualdades educativas observadas entre os grupos étnico-raciais e as populações rurais, o Plano não fixou estratégias ou metas específicas nessa direção.

O PNE previu um mecanismo de monitoramento periódico, mediante a divulgação e avaliação bienal dos programas de EJA pelos sistemas de ensino. Essa meta jamais foi tomada em consideração pelos governos, de modo que não há indicadores e relatórios que nos auxiliem a avaliar o grau de cumprimento do Plano.

\section{Uma avaliação dos progressos em direção às metas do PNE para a EJA}

$\mathrm{O}$ monitoramento dos progressos realizados em direção às metas do PNE é também, em certa medida, uma avaliação do governo do Presidente Luís Inácio Lula da Silva, já que seus dois mandatos transcorreram em oito dos dez anos de vigência da Lei n. 10.172/2001. É possível distinguir dois traços principais nas políticas de EJA do governo federal nesse período. $\mathrm{O}$ primeiro, essencialmente positivo e distintivo do governo anterior, foi a mudança da posição relativa da EJA na política educacional, atribuindo-se maior importância a esse campo, tanto no discurso quanto no organograma do governo e em suas ações. Embora a EJA continue a ocupar lugar secundário na agenda da política educacional do governo, houve um incremento na colaboração da União com os estados e municípios, por meio da institucionalização da modalidade no sistema de ensino básico, com sua inclusão nos mecanismos de financiamento e 
A educação de jovens e adultos no Plano Nacional de Educação...

nos programas de assistência aos estudantes (alimentação, transporte escolar e livro didático). ${ }^{5}$

O segundo traço dessa administração federal foi a proliferação de iniciativas de EJA geridas em diferentes instâncias de governo e precariamente articuladas entre si, entre as quais: o Programa Brasil Alfabetizado, coordenado pela Secretaria de Educação Continuada, Alfabetização e Diversidade do Ministério da Educação (MEC); o Programa Nacional de Inclusão de Jovens - PROJOvEM, gerido pela Secretaria Nacional de Juventude; o Programa Nacional de Integração da Educação Profissional com a Educação Básica na Modalidade de Educação de Jovens e Adultos, mantido pela Secretaria de Educação Profissional e Tecnológica do MEC; o Programa Nacional de Educação na Reforma Agrária, coordenado pelo Ministério do Desenvolvimento Agrário; e o Exame Nacional de Certificação de Competências, realizado pelo Instituto Nacional de Estudos e Pesquisas Educacionais (INEP).

É provável que as bases assentadas durante essa gestão garantam que a EJA ocupe um lugar mais relevante na agenda de políticas educacionais nos anos vindouros. Observado o comportamento dos indicadores educacionais, entretanto, constatamos que o ativismo desse governo no campo da EJA não foi capaz de reverter tendências anteriormente instaladas, de modo que nenhuma das cinco metas prioritárias do PNE relativas a esse campo educativo será alcançada, a começar pela superação do analfabetismo.

Embora as estatísticas populacionais registrem um crescimento no número de pessoas que participam de programas de alfabetização, repercutindo o engajamento de estados e municípios nas campanhas lideradas pelo governo federal no período, ${ }^{6}$ as taxas de analfabetismo mantiveram a tendência histórica de recuo bastante lento (Tabela 1). Nesse ritmo, o Brasil também não cumprirá, em 2015, o compromisso da iniciativa de Educação para Todos de reduzir pela metade o índice de analfabetismo de 13,6\% registrado em 2000.

Os indicadores de escolaridade comportaram-se de modo similar, com uma elevação modesta da média de anos de estudos ao longo do período, ainda situada abaixo da escolaridade obrigatória prevista na lei. A análise dos dados desagregados por grupos de idade demonstra que os pequenos progressos observados no período deveram-se mais à dinâmica demográfica do que aos efeitos das políticas e programas de EJA implementados no período. 


\section{Tabela 1}

Brasil: Analfabetismo e escolaridade da população com 15 anos ou mais (2001-2008)

\begin{tabular}{|l|c|c|c|c|c|}
\hline Indicador/Ano & 2001 & 2005 & 2006 & 2007 & 2008 \\
\hline Taxa de analfabetismo & $12,4 \%$ & $11,1 \%$ & $10,4 \%$ & $10,1 \%$ & $10,0 \%$ \\
\hline Número de analfabetos & 15.072 .313 & 14.979160 & 14.391 .064 & 14.135 .122 & 14.247 .495 \\
\hline $\begin{array}{l}\text { Inscritos em programas } \\
\text { de alfabetização }\end{array}$ & 930 mil & 1,8 milhão & 1,6 milhão & 1,3 milhão & 1,4 milhão \\
\hline Média de anos de estudos & 6,4 & 7 & 7,2 & 7,3 & 7,4 \\
\hline
\end{tabular}

Fontes: IBGE. Observatório da Equidade: <http://www.ibge.gov.br/observatoriodaequidade>; PNAD/ IBGE, citado em Relatório de Gestão da DEJA/SECAD/MEC (2009).

Esses resultados frustrantes no terreno da alfabetização são atribuídos pelas pesquisas e avaliaçôes das campanhas a pelo menos três fatores combinados: a superestimação de participantes, devida à atribuição da responsabilidade de formação de turmas aos alfabetizadores e à escassa fiscalização; problemas de focalização do programa, que inscreveria, em grande medida, pessoas já alfabetizadas e não o públicoalvo prioritário constituído por analfabetos absolutos; ${ }^{7}$ escassos resultados de aprendizagem, devidos à duração insuficiente dos cursos, à frequência intermitente e evasão dos alfabetizandos, à seleção inadequada e precária formação dos alfabetizadores, entre outros aspectos relativos à qualidade dos cursos.

O cumprimento da meta 2 do PNE, que previa a oferta de oportunidades de estudos a metade das pessoas que tinham menos de quatro anos de escolaridade, implicaria elevar as matrículas da EJA no primeiro segmento do ensino fundamental a um patamar próximo a 15 milhões de estudantes, já que pelo menos a quinta parte da população jovem e adulta encontra-se nesse grupo. As matrículas registradas nos censos escolares (Tabela 2), porém, demonstram que menos de $10 \%$ desse contingente frequenta cursos de EJA.

O cumprimento da meta 3 - que trata da garantia de que toda população que concluiu as séries iniciais tenha oportunidades de concluir o ensino fundamental - é um pouco melhor, pois em 2006 registraram-se 
A educação de jovens e adultos no Plano Nacional de Educação...

dois milhôes de matrículas no segundo ciclo do ensino fundamental da EJA, o que correspondeu a aproximadamente $12,5 \%$ das 16 milhōes de pessoas que seria necessário incorporar ao sistema educativo (Tabela 2). Surpreendentemente, a partir desse ano as matrículas da EJA entraram em declínio (Tabela 3), por razões que intrigam os pesquisadores, pois foi nesse período que se estabeleceram novas bases para o regime de colaboraçãao entre as esferas de governo, com a inclusão da modalidade no Fundo de Desenvolvimento da Educação Básica (FUNDEB) e nos programas de assistência aos estudantes.

\section{Tabela 2}

Brasil: Evolução da demanda e das matrículas da EJA no ensino fundamental (2001-2006)

\begin{tabular}{|c|c|c|c|c|}
\hline Ano & $\begin{array}{c}\text { \% da população de 15 } \\
\text { anos e mais com menos } \\
\text { de 4 anos de estudos }\end{array}$ & $\begin{array}{c}\text { Matrículas de 1a } \\
\text { a 4a séries }\end{array}$ & $\begin{array}{c}\text { \% da população de 15 } \\
\text { anos e mais com 4 a 7 } \\
\text { anos de estudos }\end{array}$ & $\begin{array}{c}\text { Matrículas de 5a } \\
\text { a 8a séries }\end{array}$ \\
\hline 2001 & $27,54 \%$ & 1.151 .429 & $30,11 \%$ & 1.485 .459 \\
\hline 2002 & $26,17 \%$ & 1.353 .463 & $29,63 \%$ & 1.434 .650 \\
\hline 2003 & $24,98 \%$ & 1.551 .018 & $28,67 \%$ & 1.764 .869 \\
\hline 2004 & $24,42 \%$ & 1.553 .483 & $27,82 \%$ & 1.866 .192 \\
\hline 2005 & $23,54 \%$ & 1.488 .574 & $27,44 \%$ & 1.906 .976 \\
\hline 2006 & $22,26 \%$ & 1.487 .072 & $26,75 \%$ & 2.029 .153 \\
\hline
\end{tabular}

Fontes: IBGE; MEC/INEP. Edudata Brasil.

Também não será alcançada a meta 16 do PNE, que propôs duplicar, em cinco anos, e quadruplicar, em dez anos, a capacidade de atendimento nos cursos de nível médio para jovens e adultos. Embora o ritmo de crescimento das matrículas na EJA de nível médio tenha sido mais intenso que na etapa do ensino fundamental, o incremento total do período 2001-2009 foi de 25\% (Tabela 3). Na verdade, a tendência de crescimento da matrícula na EJA de nível médio foi mais acentuada até 2006, período em que os estados, premidos pela escassez de 
recursos, remeteram para essa modalidade acelerada e de menor custo grande parte dos jovens que se encontravam defasados na relação idade-série. A partir da vigência do FUNDEB, as matrículas no ensino médio declinaram, estacionando em um patamar de 1,2 milhão de estudantes. Trata-se de fenômeno cuja compreensão ainda requer estudo, mas uma hipótese explicativa é que a matrícula dos jovens no ensino médio regular tornou-se mais atrativa para os sistemas de ensino, já que aí o fator de ponderação para efeito dos cálculos dos Fundos (de 1,2) é bem superior que aquele da EJA (de 0,8).

\section{Tabela 3}

Brasil: Evolução das matrículas em EJA por etapa (2001-2009)

\begin{tabular}{|c|c|c|}
\hline Ano & Ensino Fundamental & Ensino Médio \\
\hline 2001 & 2.636 .888 & 987.376 \\
\hline 2002 & 2.788 .113 & 874.001 \\
\hline 2003 & 3.315 .887 & 980.743 \\
\hline 2004 & 3.419 .675 & 1.157 .593 \\
\hline 2005 & 3.395 .550 & 1.223 .859 \\
\hline 2006 & 3.516 .225 & 1.345 .165 \\
\hline 2007 & 3.084 .718 & 1.278 .690 \\
\hline 2008 & 3.001 .834 & 1.276 .241 \\
\hline 2009 & 2.810 .738 & 1.239 .804 \\
\hline
\end{tabular}

Fonte: Censo Escolar MEC/INEP (2009).

O país ainda se encontra muito distante da meta 17 do PNE, que estipulou que todas as pessoas em privação de liberdade deveriam ter assegurado o direito ao ensino básico e profissional. De acordo com dados do Departamento Penitenciário Nacional do Ministério da Justiça para 2008, o sistema prisional tinha mais de 380 mil detentos, dos quais apenas $11 \%$ participavam de alguma atividade educacional. Nesse campo, o maior avanço realizado na última década foi a recente homologação das diretrizes nacionais para a educação nas prisões. ${ }^{8}$ 
A educação de jovens e adultos no Plano Nacional de Educação...

Os debates sobre a EJA na CONAE 2010

Visando à construção de um novo plano plurianual de educação, um ciclo de conferências municipais e estaduais deu início, em 2009, ao processo participativo que resultou na realização, em abril de 2010, da CONAE.

Nesse período, porém, grande parte dos atores sociais do campo da EJA esteve envolvida com a preparação e realização - pela primeira vez em terras latino-americanas - da VI Conferência Internacional de Educação de Adultos (CONFINTEA), reunião intergovernamental convocada pela UNESCO, que o governo brasileiro sediou em Belém (PA) em dezembro de 2009. Os Fóruns de EJA participaram ativamente das reuniōes preparatórias e da elaboração do documento nacional apresentado à VI CONFINTEA e organizações não governamentais lideradas pelo Conselho Internacional de Educação de Adultos se articularam para participar e influenciar as decisóes da Conferência, realizando, nos dias que a precederam, um Fórum Internacional da Sociedade Civil (Haddad, 2009). A mobilização brasileira em torno da VI CONFINTEA acabou por concorrer com a preparação da CONAE, na qual a rede de organizações, fóruns e ativistas do campo da EJA teve uma participação discreta.

No extenso Documento de Referência debatido pela CONAE, a EJA era mencionada brevemente no Eixo III, sobre "Democratização do acesso, permanência e sucesso escolar", e no Eixo v, que tratou do "Financiamento da educação e controle social", dedicando-se um curto tópico à temática no final do sexto e último Eixo, intitulado "Justiça Social, Educação e Trabalho: Inclusão, Diversidade e Igualdade” (Brasil, 2010a). Os enunciados eram econômicos, referindo-se basicamente à consolidação de políticas de provisão de oportunidades de alfabetização, educação básica e formação profissional de qualidade, acessíveis também às populações rurais, às pessoas deficientes e privadas de liberdade, mediante o tratamento isonômico da EJA no sistema de financiamento da educação básica e o emprego de docentes licenciados e devidamente formados.

Dessas formulações gerais, o tema mais polêmico era a isonomia de financiamento para a EJA, já que, na Conferência, participavam tanto sindicalistas, movimentos e organizações sociais que reivindicam mais recursos, quanto representantes dos governos que determinam o fator de ponderação nos cálculos do FUNDEB, até o momento fixado a seguir das 
demais etapas e modalidades da educação básica. ${ }^{9}$ Entretanto, o único debate que chegou ao plenário da CONAE referia-se a um aspecto pontual da regulamentação da modalidade, que é a elevação da idade mínima para ingresso na EJA para 18 anos.

A LDBEN n. 9.394/1996 reduziu para 15 e 18 anos, respectivamente, as idades mínimas para conclusão do ensino fundamental e do ensino médio pela via dos exames supletivos (que antes eram de $18 \mathrm{e}$ 21 anos), mas não definiu idade mínima para o ingresso na EJA. Essa lacuna foi preenchida pelo Parecer n. 11/2000 do Conselho Nacional de Educação (CNE), que fixou em 14 e 17 anos, respectivamente, as idades mínimas para ingresso na modalidade nas etapas do ensino fundamental e médio. Existe uma corrente de gestores, pesquisadores e educadores que defendem a elevação da idade mínima de ingresso na EJA para 18 anos, alegando que o ensino regular deve ser o espaço preferencial de formação dos adolescentes. Os defensores desse ponto de vista argumentam que a EJA não pode continuar a acolher toda a diversidade social e cultural rejeitadas pela escola comum, que precisaria rever os processos de exclusão dos adolescentes com defasagem na relação idade-série. Embora polêmica, essa posição prevaleceu no debate realizado pelo CNE em 2008; a Resolução então aprovada, porém, não foi homologada pelo ministro, que se alinhou aos que discordavam daquela posição, argumentando que a elevação da idade mínima de ingresso na EJA produziria ainda mais exclusão educacional, penalizando novamente os adolescentes, ao invés de induzir as mudanças desejáveis no sistema escolar educacional seletivo que os rejeitou. Em junho de 2010, o CNE reviu sua posição nas novas Diretrizes Operacionais para a EJA, em que, entre outras definiçōes, as idades mínimas de ingresso nas etapas do ensino fundamental e médio da EJA foram fixadas em 15 e 18 anos.

\section{Indicaçôes da CONAE para a EJA no PNE 2011-2020}

Em consonância com o caput da LDBEN, o Documento Final da CONAE explicita o entendimento de que a educação não se desenvolve apenas no âmbito escolar, permeando continuamente as diversas práticas sociais ao longo da vida (Brasil, 2010b, p. 29). Essa concepção abarca os múltiplos processos de formação escolar ou extraescolar, nos quais podem se engajar as pessoas jovens, adultas e idosas. 
A educação de jovens e adultos no Plano Nacional de Educação...

Reconhecendo os elevados índices de analfabetismo ainda registrados no país e a baixa escolaridade média dos brasileiros, o texto formula a proposta de que a alfabetização seja encarada como prioridade nacional (p. 70) e que os indicadores relativos à EJA sejam considerados no ordenamento da colaboração da União com os entes federados (p. 23).

No eixo III, que tratou da "democratização do acesso, permanência e sucesso escolar", o Documento Final reiterou as formulações gerais contidas no Documento de Referência mencionadas anteriormente, colocando ênfase na articulação entre a formação geral e profissional (p. 65), inclusive por meio da ampliação dos cursos gratuitos oferecidos pelo "Sistema S"10 (p. 73).

Em meio às numerosas propostas do Eixo IV para a "Formação e valorização dos/das profissionais da educação", consta a diretriz de formação continuada dos profissionais do magistério atuantes na EJA, com vistas a uma prática pedagógica conforme as especificidades dos sujeitos da aprendizagem (p. 88). Para superar o quadro atual de rotatividade e precariedade do vínculo de trabalho, propóe-se valorizar os profissionais que possuem formação e atuam na EJA, mediante justa remuneração e adoção de critérios de seleção, ingresso e progressão na carreira que estimulem a dedicação e permanência dos docentes na modalidade (p. 89).

A regulamentação do custo aluno-qualidade (CAQ) diferenciado é, ao lado do aumento dos recursos vinculados à educação, da reforma tributária e da Lei de Responsabilidade Fiscal, uma das estratégias indicada no Eixo v, que trata do financiamento da educação. Para criar condições de melhoria da qualidade e ampliação da oferta de EJA, o documento defende a eliminação do teto de gastos e isonomia de tratamento no FUNDEB, o que permitiria ampliar os recursos a ela destinados (p. 116).

O tópico dedicado à EJA no Eixo VI, intitulado "Justiça Social, Educação e Trabalho: Inclusão, Diversidade e Igualdade”, foi ampliado em mais de dez páginas, nas quais se distribui - sem qualquer hierarquia - um extenso rol de proposições de diferentes ordens, relativas às concepçôes pedagógicas, ao planejamento e às estratégias de políticas públicas, à ampliação da oferta e do financiamento, melhoria da infraestrutura, da formação inicial e continuada dos educadores e das 
condições de trabalho docente, consideração da diversidade dos educandos, fiscalização do setor privado, produção de estatísticas e pesquisas, supervisão e normas, organização escolar, currículos, materiais e meios de ensino. A Conferência também incluiu todo um tópico sobre a educação básica e profissional das pessoas privadas de liberdade. Fica a impressão de que, para contrapor-se à redação enxuta e compensar o último lugar atribuído à EJA do Documento de Referência, a plenária do Eixo VI optou por acolher toda sorte de propostas, sem estabelecer entre elas uma escala de prioridades, o que dificulta sua tradução em um número limitado de diretrizes e metas no novo PNE.

Desafios a serem enfrentados pelas políticas públicas e planos de educação

O processo de construção do novo PNE oferece uma oportunidade para enfrentarmos com um olhar renovado, crítico e esperançoso alguns dos antigos desafios colocados para que os direitos educativos dos jovens, adultos e idosos sejam assegurados.

Para não cair no lugar comum e simplesmente postergar para a próxima década metas de "erradicação" do analfabetismo (como se esse fenômeno sociocultural complexo fosse uma enfermidade exógena passível de cura com remédio fácil), convém reavivar o debate das concepções de formação e alfabetização de jovens e adultos, em suas conexôes com o desenvolvimento socioeconômico e o exercício da cidadania. Já há tempos os estudiosos salientam a necessidade de superar as abordagens setoriais que pretendem vencer o analfabetismo e a reduzida escolaridade da população sem atuar conjuntamente sobre as condições estruturais de exclusão política, socioeconômica e cultural que geram e reproduzem tais fenômenos (Soares, 1990; GLEACE, 2009).

Um desafio relacionado a essa questão reside na dificuldade de mobilizar a demanda social por EJA, aproximando as cifras milionárias da população que potencialmente demandaria oportunidades de formação e aquela reduzida parcela dos jovens, adultos e idosos que efetivamente têm participado dos cursos disponíveis. Em uma primeira instância, a expressão da demanda social reflete a disponibilidade, acessibilidade e publicidade dos serviços educativos existentes, bem como sua qualidade e adequação às múltiplas necessidades formativas da população. 
A educação de jovens e adultos no Plano Nacional de Educação...

Entretanto, é preciso considerar que a motivação e a mobilização para os estudos na idade adulta relacionam-se não só às exigências de formação da vida cotidiana e à quantidade e qualidade das oportunidades de atendê-las, mas também aos horizontes de mudança socioeconômica e nas estruturas de poder, o que depende de políticas participativas e redistributivas que transcendem a esfera educacional.

É tempo de reavaliar, também, as visões que reduzem a EJA à alfabetização e que, ao fazê-lo, encaram os fenômenos do analfabetismo e da alfabetização em uma perspectiva dicotômica (quando, na verdade, trata-se de um continuum), descurando da qualidade e continuidade de estudos e da ampliação do acesso à cultura escrita, necessários à consolidação das aprendizagens iniciadas. A corrida atrás das metas quantitativas apoiada nessas visões acaba por justificar estratégias de campanha em que persiste

(...) uma concepção simplista e facilista da alfabetização, vista como um processo que pode ser realizado em pouco tempo, em condições precárias, com educadores sem ou com mínima capacitação, com métodos únicos, escassos materiais de leitura e escrita, pouco aproveitamento das modernas tecnologias; e sem levar em conta a diversidade linguística e cultural dos educandos. (GLEACE, 2009)

Para que as políticas públicas possam conferir materialidade a concepções mais apropriadas de alfabetização e educação básica de qualidade (o que implica também articular devidamente oportunidades de qualificação profissional e acesso às tecnologias da comunicação e informação), é preciso ampliar o financiamento destinado à EJA e reverter a situação de despreparo e desvalorização profissional dos educadores que a ela se dedicam.

Quanto aos recursos financeiros, um bom começo seria assegurar que o fator de ponderação da EJA no FUNDEB fosse equiparado às demais modalidades da educação básica, enquanto estudos empíricos rigorosos apuram qual seria seu efetivo CAQ. Um financiamento mais adequado é pré-condição para superar a situação vigente na atualidade, pela qual, sob o biombo artificial do "voluntariado", pessoas sem a necessária formação pedagógica são convocadas a atuar como alfabetizadoras com remuneração inferior ao piso salarial nacional da categoria.

Ao lado do estabelecimento de condições mínimas de trabalho profissional, a formação de educadores é um dos grandes desafios a 
serem encarados pelas políticas educacionais nos próximos anos. O governo federal tentou, a partir de 2006, avançar nessa direção, promovendo cursos de especialização em EJA e realizando chamadas para que instituiçõos públicas de ensino superior participassem de uma rede nacional de prestação de serviços de formação continuada de educadores, quase sempre na modalidade a distância. Nenhuma dessas estratégias foi capaz, até o momento, de induzir as universidades a incorporar, de modo duradouro, em sua missão e currículos a formação inicial e continuada de educadores de jovens e adultos, de tal modo que persiste a situação em que esse campo de conhecimento é omitido ou tratado marginalmente nos cursos de habilitação de professores (Gatti \& Nunes, 2009). Para reverter esse quadro, seria necessário aprovar legislação ou norma específica e acionar mecanismos mais eficientes de indução. ${ }^{11}$

Resta ainda o desafio de aperfeiçoamento do regime de colaboração, que permita superar a situação atual de desarticulação de iniciativas, imposição aos governos subnacionais de programas federais prémodelados, em que os municípios são impelidos a assumir encargos crescentes na provisão da EJA sem o necessário respaldo técnico e financeiro da União e dos estados. Ainda não é possível avaliar o impacto da iniciativa do MEC de articulação da Agenda Territorial de Alfabetização e EJA em cada unidade federada, mas é legítimo supor que uma estratégia isolada para a modalidade tenha menos chance de êxito do que um processo institucional de planejamento sistêmico que articule, nos próximos anos, os planos nacional, estaduais e municipais de Educação.

Recebido e aprovado em agosto de 2010.

\section{Notas}

1. Como os objetivos da iniciativa não foram alcançados na década de 1990 , os compromissos foram renovados no Fórum Mundial de Dacar, em 2000, e as metas postergadas para 2015.

2. O PAS associava recursos federais aos da filantropia empresarial e colaboração de instituições de ensino superior para uma campanha de alfabetização direcionada aos municípios com maiores índices de analfabetismo. Ao final do governo, passou a funcionar como organização social.

3. Iniciado em 2001, o Programa Recomeço operava transferência de recursos federais a estados e municípios com baixos índices de desenvolvimento humano para aquisição de equipamentos, materiais didático-pedagógicos e capacitação de professores. 
A educação de jovens e adultos no Plano Nacional de Educação...

4. Critério estatístico adotado pela UNESCO para designar o limitado domínio da leitura e escrita de pessoas com menos de quatro anos de estudos.

5. Referimo-nos à Emenda que criou, em 2006, o Fundo de Desenvolvimento da Educação Básica (FUNDEB) e à Lei n. 11.497/2009, que regulamentou a inclusão da modalidade no Programa Dinheiro Direto na Escola, bem como as resoluções do Fundo Nacional de Desenvolvimento da Educação que incluíram, progressivamente, entre 2004 e 2009, a modalidade nos Programas Nacionais do Livro Didático, de Alimentação e de Transporte Escolar.

6. Trata-se dos programas Alfabetização Solidária e Brasil Alfabetizado, desenvolvidos, respectivamente, pelos governos dos presidentes Fernando Henrique Cardoso, no período 1998/2002, e Luís Inácio Lula da Silva, de 2003 aos dias atuais.

7. A proporção de pessoas inscritas no Brasil Alfabetizado que já haviam frequentado escolas anteriormente variou de 38,7\% em 2005 a 42,5\% em 2008, evidenciando que o Programa vem atendendo a pessoas com baixa escolaridade, mas não necessariamente os analfabetos absolutos. A taxa de evasão do Brasil Alfabetizado em 2005 (único ano para o qual se dispóe dos dados) foi de 17\% (Fontes: IBGE e SECAD, apud Observatório da Equidade: http://www.ibge.gov.br/observatoriodaequidade).

8. Trata-se do Parecer n. 4/2010, da Câmara de Educação Básica do Conselho Nacional de Educação.

9. A lei que regulamentou o FUNDEB estipulou que a EJA fosse incluída progressivamente (33\% das matrículas ao ano) no período 2007-2009. Também fixou um teto de gasto na modalidade de $15 \%$ do valor total do Fundo. Inicialmente, foi atribuído o fator de ponderação 0,7 à modalidade (de modo indiferenciado nas diferentes etapas do ensino básico), fator este elevado posteriormente para 0,8 .

10. Rede formada pelo Serviço Social da Indústria (SESI), Serviço Nacional de Aprendizagem Industrial (SENAI), Serviço Nacional Comercial (SENAC) e Serviço Nacional Rural (SENAR), entre outros.

11. A Coordenação de Aperfeiçoamento do Pessoal do Ensino Superior (CAPES) e o Conselho Nacional de Desenvolvimento Científico e Tecnológico (CNPq) são agências que dispõem de meios para influir na configuração dos cursos superiores.

\section{Referências}

BEISIEGEL, C. A educação de jovens e adultos analfabetos no Brasil. Alfabetização e Cidadania, São Paulo, n. 16, p. 19-27, jul. 2003.

BRASIL. Ministério da Educação. Secretaria de Educação Continuada, Alfabetização e Diversidade. Documento nacional preparatório a VI Conferência Internacional de Educação de Adultos (VI CONFINTEA). Brasília, DF: MEC; Goiânia: FUNAPE/UFG, 2009.

CONFERÊNCIA INTERNACIONAL SOBRE EDUCAÇÃO DE ADULTOS, 5., 1997, Hamburgo, Alemanha. Declaração de Hamburgo 
e agenda para o futuro. Lisboa: UNESCO; Ministério da Educação; Ministério do Trabalho e Solidariedade, 1998.

CONFERÊNCIA NACIONAL DE EDUCAÇÃO (CONAE), 2010, Brasília, DF. Construindo o Sistema Nacional Articulado de Educação: o Plano Nacional de Educação, diretrizes e estratégias; Documento de Referência. Brasília, DF: MEC, 2010a.

CONFERÊNCIA NACIONAL DE EDUCAÇÃO (CONAE), 2010, Brasília, DF. Construindo o Sistema Nacional Articulado de Educação: o Plano Nacional de Educação, diretrizes e estratégias; Documento Final. Brasília, DF: MEC, 2010b.

CURY, C.R.J. Parecer CNE/CEB n. 11/2000, que dispõe sobre as diretrizes curriculares para a educação de jovens e adultos. Brasília, DF: MEC/ CNE, 2000.

DELORS, J. Educação: um tesouro a descobrir. São Paulo: Cortez, 1998.

DI GIORGI, C. et al. A educação básica no Plano Nacional de Educação. Cadernos do Observatório, Rio de Janeiro, n. 3, p. 49-77, dez. 2001.

DI PIERRO, M.C. Descentralização, focalização e parceria: uma análise das tendências nas políticas públicas de educação de jovens e adultos. Educação \& Pesquisa, São Paulo, v. 27, n. 2, p. 321-337, jul./ dez. 2001.

DI PIERRO, M.C. Notas sobre a redefinição da identidade e das políticas públicas de educação de jovens e adultos no Brasil. Educação \& Sociedade, Campinas, v. 26, n. 92, p. 1115-1139, 2005.

DI PIERRO, M.C. Luta social e reconhecimento jurídico do direito humano dos jovens e adultos à educação. Revista Educação, Santa Maria, v. 33, n. 3, p. 395-410, set./dez. 2008. Disponível em: <http:// www.ufsm.br/revistaeducacao $>$.

DI PIERRO, M.C. Balanço e desafios das políticas públicas de educação de jovens e adultos no Brasil. In: SOAReS, L. et al. (Org.). Convergências e tensões no campo da formação e do trabalho docente: educação de jovens e adultos. Belo Horizonte: Autêntica, 2010. p. 27-43. 
A educação de jovens e adultos no Plano Nacional de Educação...

DI PIERRO, M.C.; ABBONIZIO, A.C.O.; GRACIANO, M. Seis anos de educação de jovens e adultos no Brasil. São Paulo: Ação Educativa, 2004.

DI PIERRO, M.C.; GRACIANO, M. Educación de personas jóvenes y adultas en Brasil. In: LA EDUCACIÓN de jóvenes y adultos en América Latina y el Caribe: hacia un estado del arte. Santiago do Chile: UNESCO/OREALC; Hamburgo: UIE/UNESCO, 2003. p. 63-98.

DI PIERRO, M.C.; VOVIO, C.L.; ANDRADE, E.R. Alfabetização de jovens e adultos: lições da prática. Brasília, DF: UNESCO, 2008.

EDUCAÇÃO para todos: o compromisso de Dakar. Brasília, DF: unesco, CONSED; São Paulo: Ação Educativa, 2001.

GATTI, B.A.; NUNES, M.N.R. Formação de professores para o ensino fundamental: estudo de currículos das licenciaturas em Pedagogia, Língua Portuguesa, Matemática e Ciências Biológicas. São Paulo: FCC, 2009 (Textos FCC, v. 29).

GRUPO LATINO-AMERICANO DE ESPECIALISTAS EM ALFABETIZAÇÃO E CULTURA ESCRITA (GLEACE). Declaração sobre analfabetismo e alfabetização. 2009. Disponível em: <http://www. scribd.com/doc/22896417/GLEACE-Declaracao-sobre-Analfabetismo-eAlfabetizacao>.

HADDAD, S. A participação da sociedade civil brasileira na educação de jovens e adultos e na CONFINTEA VI. Revista Brasileira Educação, Rio de Janeiro, v. 14, n. 41, p. 355-369, ago. 2009.

HADDAD, S.; DI PIERRO, M.C. An historical overview of adult formal education in Brazil. In: Castro, R.V.; Sancho, A.V.; GuimaRÃES, P. (Ed.). Adult education: new routes in a new landscape. Braga: Universidade do Minho, 2006. p. 231-270.

MONLEVADE, J. Plano Nacional de Educação ou carta de intençôes? Cadernos do Observatório, Rio de Janeiro, n. 3, p. 17-31, dez. 2001 .

PAIVA, J.; MACHADO, M.M.; IRELAND, T. (Org.). Educação de jovens e adultos: uma memória contemporânea (1996-2004). Brasília, DF: UNESCO/MEC, 2004. 
PINTO, J.M.R. Financiamento da educação no Brasil: um balanço do governo FHC (1995-2002). Educação \& Sociedade, Campinas, v. 23, n. 80 , p. $108-135$, set. 2002.

SOARES, L.J.G. Os Fóruns de Educação de Jovens e Adultos: articular, socializar e intervir. Presença Pedagógica, Belo Horizonte, v. 9, n. 54, p. 15-21, 2003.

SOARES, L.J.G. Formação de educadores: a habilitação em EJA nos cursos de Pedagogia. In: SOARES, L. et al (Org.). Convergências e tensões no campo da formação e do trabalho docente: educação de jovens e adultos. Belo Horizonte: Autêntica, 2010. p. 78-99.

SOARES, M.B. Universidade, cidadania e alfabetização. Caminhos, Belo Horizonte, n. 1, p. 37-41, jun. 1990.

TORRES, R.M. Aprendizaje a lo largo de toda la vida: un nuevo momento y una nueva oportunidad para el aprendizaje y la educación básica de las personas en el sur. Buenos Aires: ASDI, 2002. 